\title{
Distribution and Ecological Drivers of Spotted Fever Group Rickettsia in Asia
}

\author{
Jaruwan Satjanadumrong, ${ }^{1}$ Matthew T. Robinson, ${ }^{2,3}$ Tom Hughes, ${ }^{1,4}$ and Stuart D. Blacksell $\oplus^{1,2,3}$
}

\begin{abstract}
${ }^{1}$ Mahidol-Oxford Tropical Medicine Research Unit, Faculty of Tropical Medicine, Mahidol University, 420/6 Rajvithee Road, Bangkok 10400, Thailand
${ }^{2}$ Lao-Oxford-Mahosot Hospital-Wellcome Trust Research Unit (LOMWRU), Mahosot Hospital, Vientiane, Lao People's Democratic Republic

${ }^{3}$ Centre for Tropical Medicine and Global Health, Nuffield Department of Clinical Medicine, Churchill Hospital, University of Oxford, Oxford OX3 $7 F Z, U K$

${ }^{4}$ EcoHealth Alliance, 460 West 34th Street, 17th Floor, New York, NY
\end{abstract}

\begin{abstract}
Spotted fever group and related rickettsia (SFGR) are a neglected group of pathogens that belong to the genus Rickettsia. SFGR are zoonotic and are transmitted by arthropod vectors, primarily ticks, fleas and mites to accidental hosts. These emerging and re-emerging infections are widely distributed throughout the world. Land-use change and increasing human-wildlife conflict compound the risk of SFGR infection to local people in endemic areas and travelers to these regions. In this article, we discuss the rickettsial organisms causing spotted fever and related diseases, their arthropod vectors in Asia and the impact of land-use change on their spread.
\end{abstract}

Keywords: Spotted fever rickettsia, Rickettsial infection, Land-use change, Diagnosis, Asia

\section{INTRODUCTION}

Rickettsioses are infectious diseases caused by obligate intracellular gram-negative bacteria. They belong to the order of Rickettsiales, family Rickettsiaceae (Fournier and Raoult 2009) and reside in a wide range of arthropod vectors such as fleas, ticks and mites (Chikeka and Dumler 2015; Merhej et al. 2014). These vectors can transmit pathogens to humans at the bite site, who may or may not subsequently develop disease. Rickettsial diseases have been reported to be the second most common cause of nonmalarial febrile illness in the Southeast Asia region after dengue infection (Acestor et al. 2012).

Published online: April 15, 2019

Correspondence to: Stuart D. Blacksell, e-mail: stuart@tropmedres.ac
The family Rickettsiaceae comprises Rickettsia and Orientia genera as members and is divided into three major groups; spotted fever group (SFGR), typhus group (TG) and scrub typhus group (STG) (Bhengsri et al. 2016). Rickettsial diseases have worldwide distribution although there are endemic and hyper-endemic areas (Chikeka and Dumler 2015; Luce-Fedrow et al. 2015; Merhej et al. 2014). Typhus group and scrub typhus group are widely diagnosed in Southeast Asia (Aung et al. 2014; Parola et al. 2013; Rodkvamtook et al. 2013). In Asia, typhus group infections are primarily caused by Rickettsia typhi which is the etiologic agent of murine typhus (endemic typhus) with a few cases of epidemic or louse-borne typhus caused by $R$. prowazekii reported. Scrub typhus is widespread in AsiaPacific and northern Australia and is caused by Orientia 
tsutsugamushi along with the related O. chuto (Chikeka and Dumler 2015; Izzard et al. 2010).

SFGR consists of at least 30 species that can be found worldwide. Twenty-one species are identified as pathogens: R. rickettsii, $R$. parkeri, $R$. africae, $R$. massiliae, $R$. philipii, $R$. conorii, $R$. sibirica, $R$. slovaca, $R$. raoultii, $R$. monacensis, $R$. aeschlimannii, $R$. helvetica, $R$. heilongjiangensis, $R$. japonica, $R$. honei, $R$. tamurae, Candidatus Rickettsia kellyi, $R$. australis, $R$. mongolotimonae, $R$. felis and $R$. akari. Nine species are of unknown pathogenicity: Candidatus Rickettsia asemboensis, $R$. bellii, $R$. montanensis, $R$. peacockii, $R$. rhipicephali, $R$. monteiroi, $R$. gravesii, and $R$. argasii (Fournier and Raoult 2009; Merhej et al. 2014). There remains some conjecture as to the status of $R$. felis and $R$. akari within SFGR (Chikeka and Dumler 2015). There is an argument that $R$. felis and $R$. akari should be reclassified into a transitional group (Gillespie et al. 2008) on the basis of phylogenetic analysis, however, at this point in time they remain classified as members of the SFGR (Fournier and Raoult 2009; Merhej et al. 2014; Vitorino et al. 2007).

The most well-known rickettsia is $R$. rickettsii which causes Rocky Mountain Spotted Fever (RMSF) and causes human infections predominantly in the USA (Kato et al. 2013). Other species such as $R$. australis and $R$. honei are prevalent in northern Australia (Graves and Stenos 2009). Rickettsia conorii is responsible for Mediterranean Spotted Fever (MSF) in several parts of Europe, Africa and Asia (Nanayakkara et al. 2013; Niang et al. 1998; Parola 2004).

The main arthropod vectors of SFGR are ticks, predominantly hard ticks (Ixodidae) that bite animals and humans (Luce-Fedrow et al. 2015; Parola et al. 2013). Transmission of the pathogens occurs via salivary products produced during feeding of infected vectors on the wound or mucosal surfaces. Non-validated, incompletely described, or uncultivated SFGR species have also been isolated or detected in soft ticks (Argasidae) (Parola et al. 2013); however, the competency to transmit disease is uncertain. Rickettsial infection occurs following infection of the endothelial cell lining of blood vessels (microvascular endothelium infected by $R$. conorii and both microvascular and macrovascular endothelium by $R$. rickettsii) (Colonne et al. 2011; Rydkina et al. 2010).

The purpose of this article is to discuss the distribution of SFGR in Asia, the arthropod vectors and the impact of land-use change on the spread of SFGR disease emergence.

\section{SFGR INFECTION AND DIAGNOSIS}

\section{Geographical Distribution in Asia}

SFGR are considered to be neglected diseases which are recently emerging or re-emerging infections in several areas of the world, especially in developing countries across Asia (Chikeka and Dumler 2015). The distribution of SFGR based on previous reports is presented in Table 1 and Figure 1.

In Southeast Asia, both animals and humans are infected by SFGR. One of the earliest reports was in 1962 when Rickettsia sp. TT-118 was identified from a mixed pool of Ixodes granulatus ticks and Rhipicephalus spp. larval ticks, collected from rats (Rattus rattus) in the north region of Thailand (Chaingmai province) (Jiang et al. 2005; Robertson and Wisseman 1973). TT-118 is a homologous strain of R. honei, the pathogen of Flinders Island spotted fever (Stenos et al. 1998), and was reported in Thailand from a patient by sequencing of amplicons from five rickettsial genes to identify the species (Jiang et al. 2005). Human SFGR infection by $R$. honei has been reported in tropical countries such as Thailand and Malaysia (Okabayashi et al. 1996; Tay et al. 2003; Tee et al. 1999). Additionally, $R$. thailandii has been reported, but the pathogenic potential is not defined (Kollars et al. 2001). R. felis was first reported in Thailand in 2002 from Ctenocephalides felis, the main arthropod vector of the causative agent of cat-flea typhus or flea-borne spotted fever (Edouard et al. 2014). There are several human cases of $R$. felis reported in Thailand, Taiwan (Kuo et al. 2015; Lai et al. 2014; Tsai et al. 2008), Cambodia (Inpankaew et al. 2016), Japan (Perez-Osorio et al. 2008), Malaysia (Tay et al. 2014) and Laos (Dittrich et al. 2014). Besides R. felis, other SFGR have also been detected, such as R. helvetica, Rickettsia sp. $A T 1$ and R. conorii (in particular R. conorii subsp. indica) in Laos (Dittrich et al. 2014; Phongmany et al. 2006; Varagnol et al. 2009). Rickettsia japonica, the pathogen of Japanese spotted fever infection, has been reported in Asian countries including Japan (Fournier et al. 2002), Taiwan (Tsai et al. 2008), Thailand (Okabayashi et al. 1996) and Laos (Taylor et al. 2016). In the Philippines, human antibodies against $R$. japonica have been reported (Camer et al. 2003). Rickettsia conorii, the causative pathogen of Mediterranean spotted fever (MSF), has been detected in Indonesia (Richards et al. 2003) and the Thailand-Burma border (Parola et al. 2003b). Three novel species were recently found in Laos which are Candidatus Rickettsia laoensis, Candidatus 


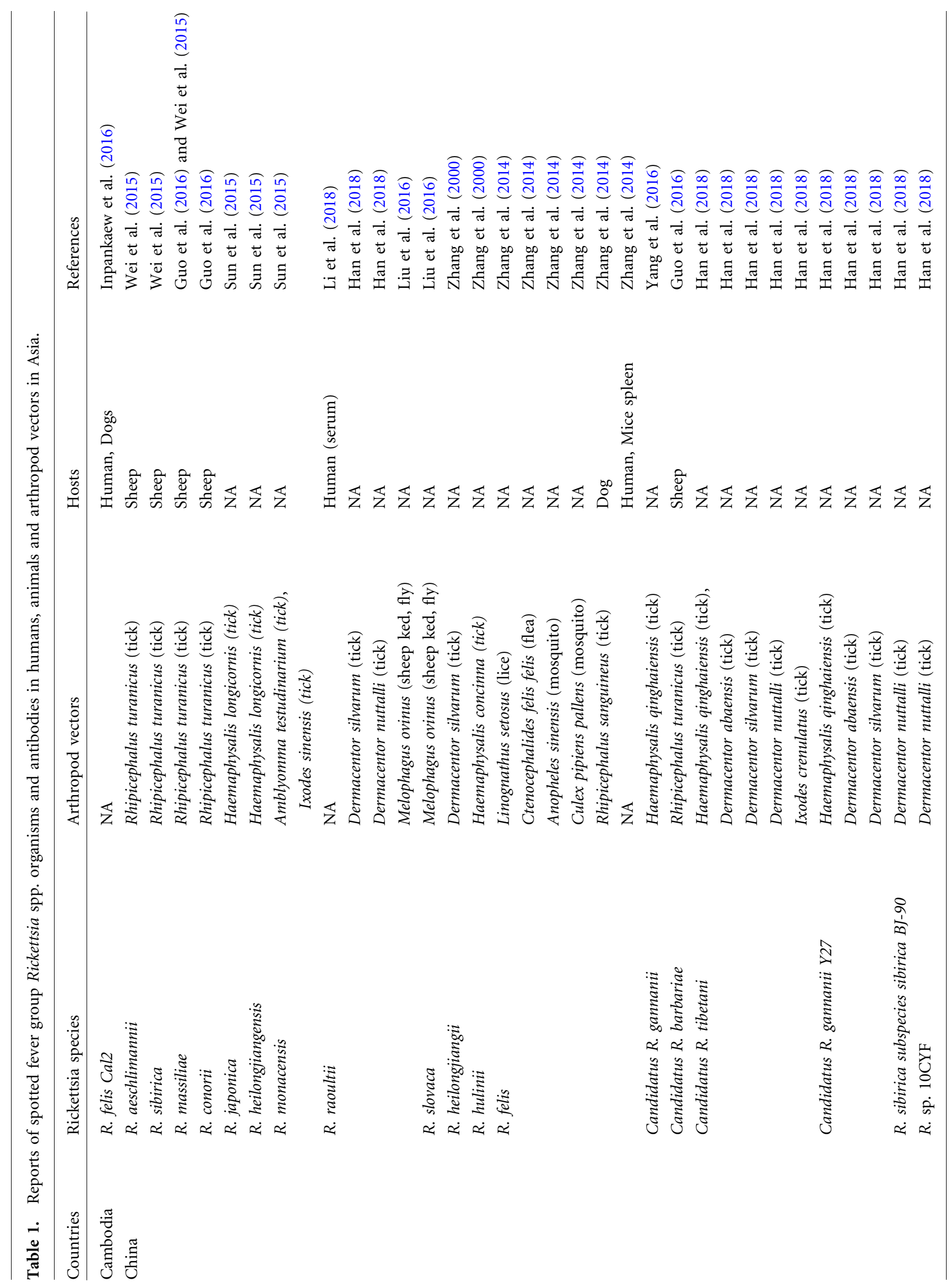




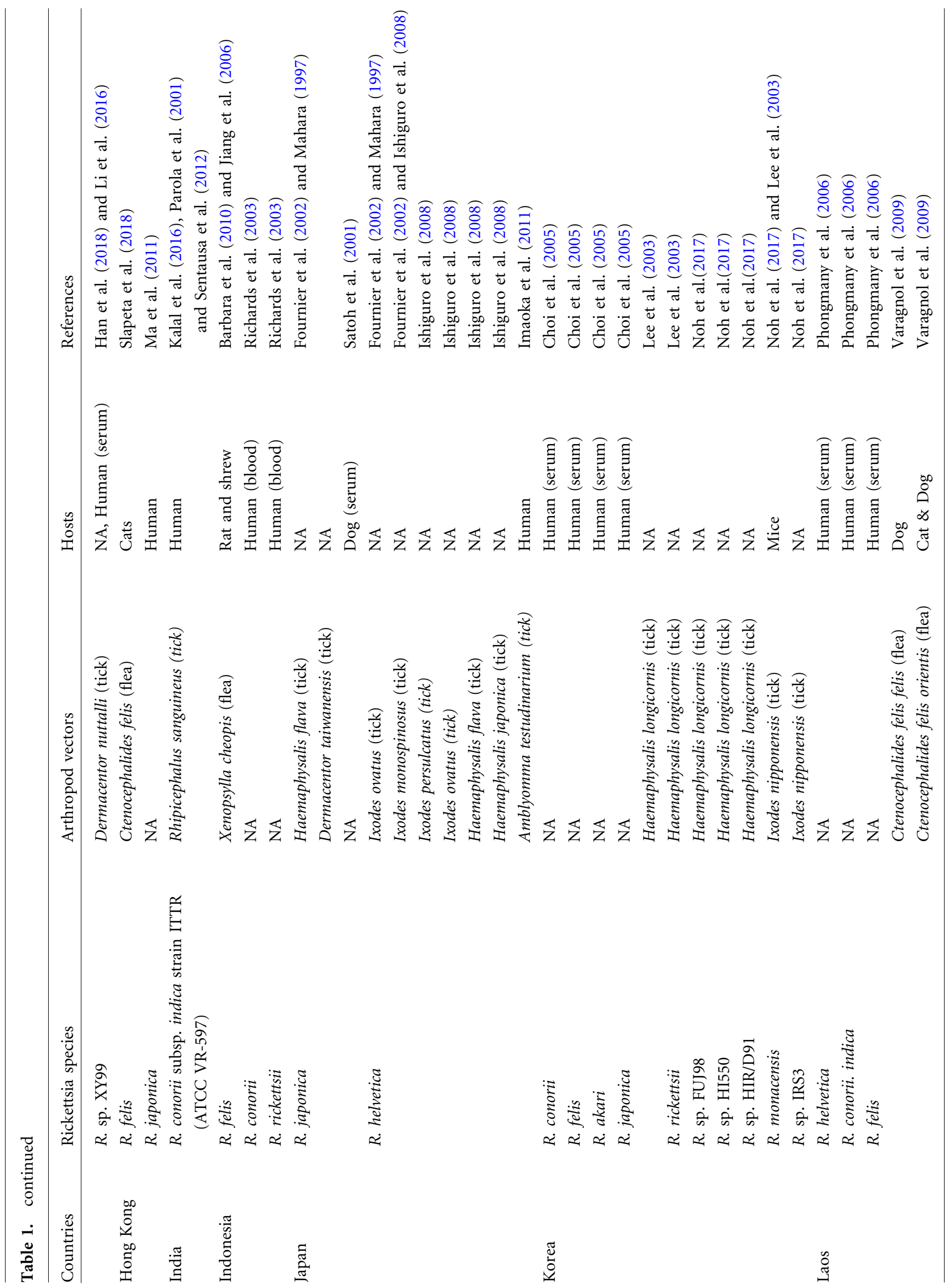




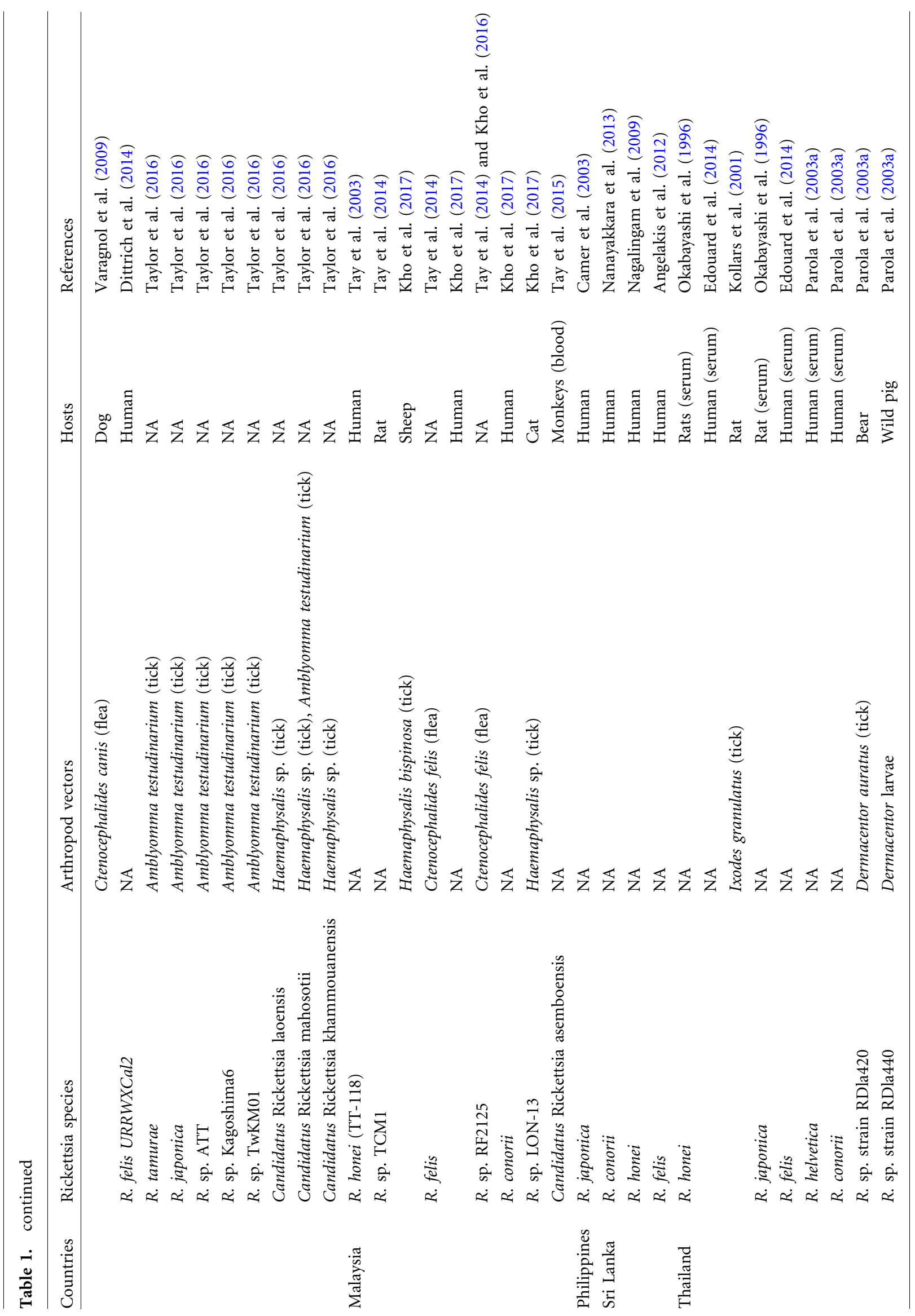




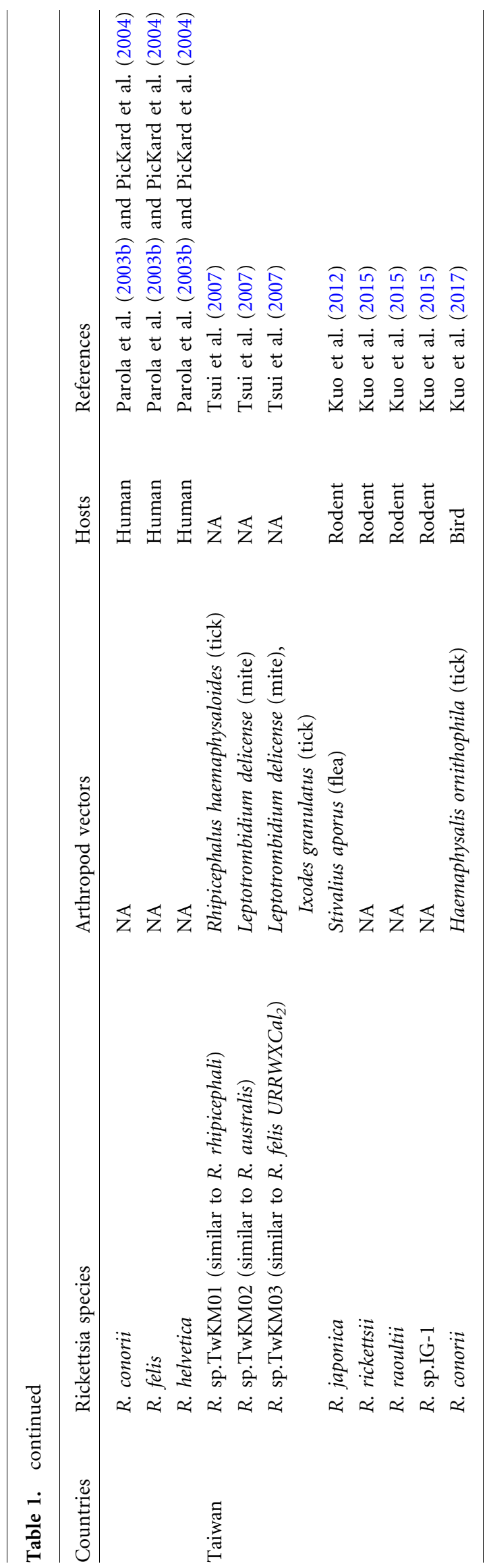

Figure 1. Geographical distribution of reported detections of spotted fever group Rickettsia spp. organisms and antibodies in humans, animals and arthropod vectors in Asia.

Rickettsia mahosotii and Candidatus Rickettsia khammouanensis (Taylor et al. 2016). In Sri Lanka, located in South Asia, SFGR R. felis, $R$. honei, $R$. conorii, $R$. helvetica, $R$. japonica and R. slovaca antibodies have been detected in both humans and canines (Kularatne et al. 2003; Nagalingam et al. 2009; Nanayakkara et al. 2013).

In Northeast/East Asia, SFGR species have been detected throughout China such as $R$. felis, R. sibirica, $R$. massiliae, $R$. raoultii, $R$. aeschlimannii, $R$. heiongjiangii, $R$. hulinii and $R$. mongolotimonae (Han et al. 2018; Li et al. 2018; Wei et al. 2015; Yang et al. 2016; Zhang et al. 2000, 2014). In 2015, a novel genotype of SFGR was reported as Rickettsia sp. XY99 from ill patients (Li et al. 2016). Candidatus Rickettsia gannanii and Candidatus Rickettsia barbariae were discovered and suggested to be emerging SFGR species in China (Guo et al. 2016; Yang et al. 2016). Rickettsia felis, R. japonica and other SFGR species have been identified in Hong Kong, Japan, Korea and Taiwan (Table 1) (Fournier et al. 2002; Noh et al. 2017; Slapeta et al. 2018; Tsai et al. 2008).

Seroprevalence studies have been used to determine exposure in community or hospital settings to SFGR (Table 2). In Malaysia, prevalence of TT-118 SFGR was $57.3 \%$ (Tee et al. 1999) and 12.9\% (Tay and Rohani 2002). In South Korea, prevalence against $R$. siribica, $R$. conorii and $R$. akari was $38.6 \%$ (Jang et al. 2005). In Sri Lanka, seroprevalence studies of SFGR have found an increase in prevalence from 35 to 66\% during 2000-2008 (Kularatne et al. 2013; Premaratna et al. 2008, 2014). Increasing prevalence of SFGR is also noted in central India compared to south and northeast regions (69.3\%, 37.1\% and $13.8 \%$, respectively) (Kalal et al. 2016; Khan et al. 2016; Rathi et al. 2011). It should be noted that due to extensive cross-reaction within SFGR (Hechemy et al. 1989), it is generally not possible to identify the species level using serological methods unless cross-adsorption techniques are used (La Scola and Raoult 1997), and therefore, results should be interpreted with caution.

\section{SFGR EPIDEMIOLOGY}

\section{Vectors}

In Asia, Dermacentor spp. and Haemophysalis spp. (from the family of Ixodidae, or hard ticks) are most frequently 


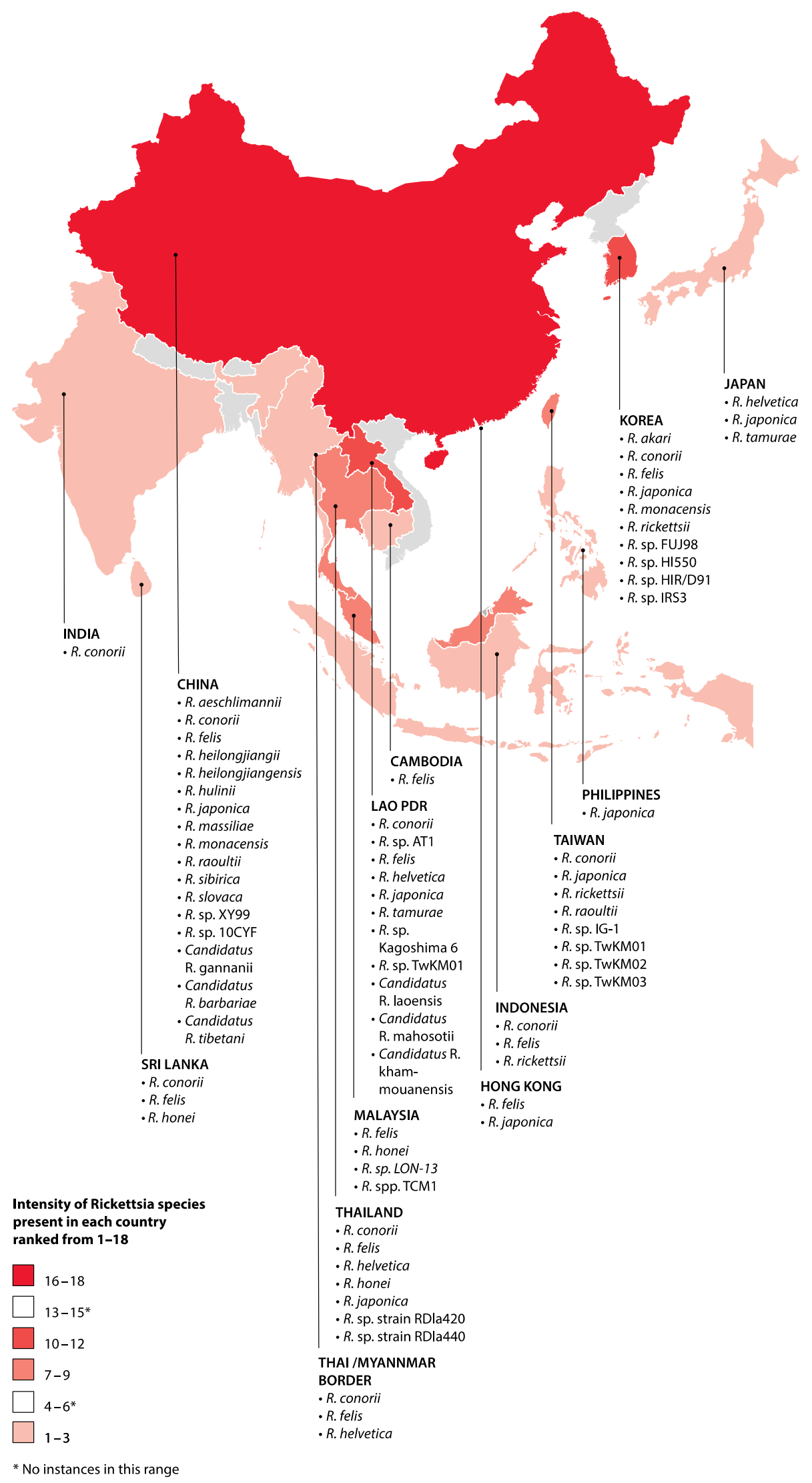




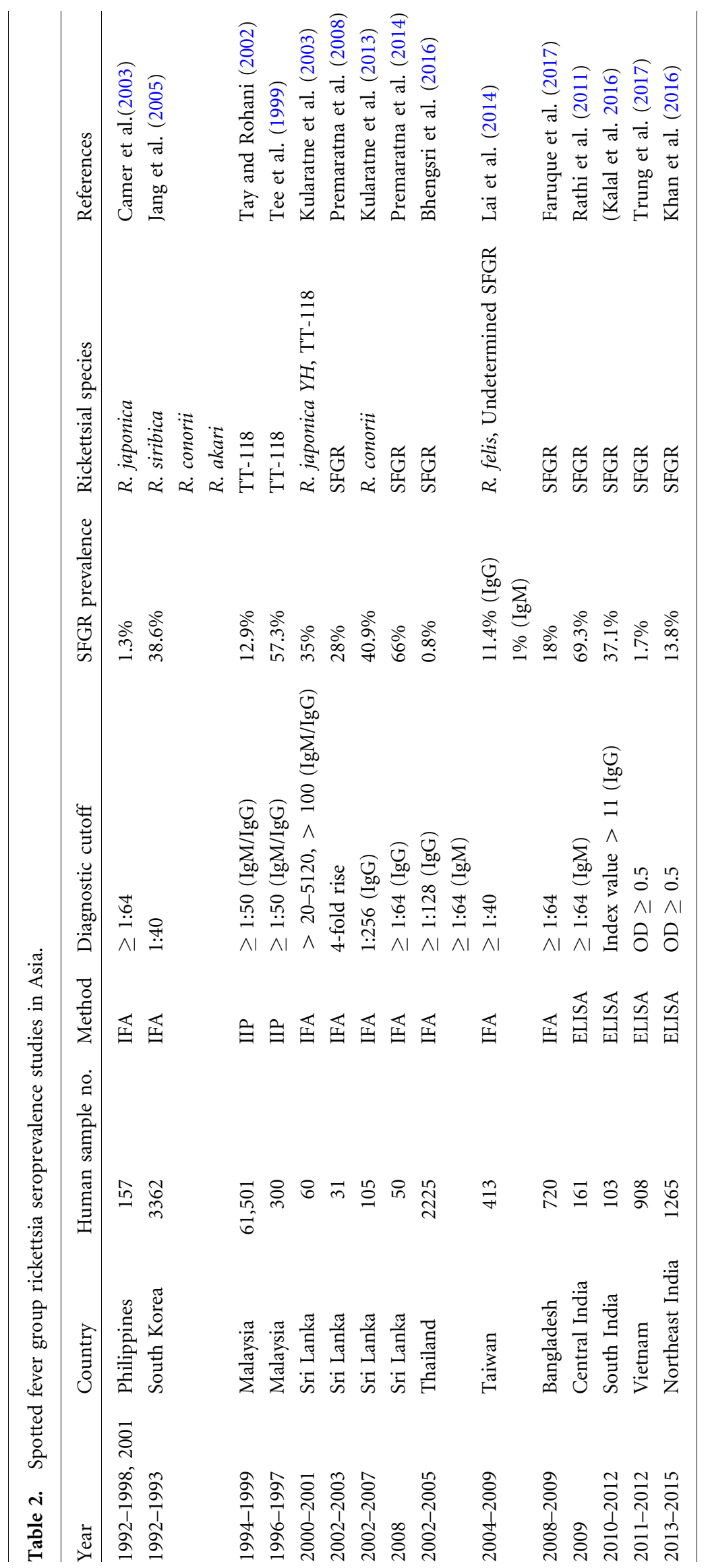


associated with rickettsial carriage in Asia, but others also include Ixodes spp., Ambylomma spp., and Rhipicephalus spp. (Table 1). Of the 22 tick species identified to carry SFGR (Table 1), their distribution is more widespread than indicated. Amblyomma testudinarium, identified in China, Japan and Laos as a vector of SFGR such as $R$. monacensis and R. japonica (Sun et al. 2015; Taylor et al. 2016) (Table 1 ), is the most widespread of the hard ticks and has also been found in India, Myanmar, Thailand, Malaysia, Indonesia, Philippines, Taiwan, Japan and Korea. Rhipicephalus sanguineus, a SFGR vector in China and India known to harbor $R$. conorii and R. felis (Zhang et al. 2014; Kalal et al. 2016; Sentausa et al. 2012; Parola et al. 2001), is also known for its worldwide distribution (Gray et al. 2013). The longhorned tick (Haemaphysalis longicornis) is found on livestock including cattle, pigs and chickens but also on wildlife including deer, small mammals including rats, and on cats, dogs and humans (Cane 2010). Longhorned ticks have been demonstrated to carry $R$. japonica (Sun et al. 2015; Lee et al. 2003), R. heilongjiangensis (Sun et al. 2015), R. rickettsii (Lee et al. 2003), Rickettsia sp. FUJ98, Rickettsia sp. HI550 and Rickettsia sp. HIR/D91 (Noh et al. 2017). It should be noted that the detection of rickettsia in the above-mentioned vectors does not imply that they are capable of transmission to hosts; therefore, it is necessary to study vector competence and capacity to better understand the threat associated with each vector.

For the Siphonaptera, Ct. felis is the most common rickettsial vector predominantly responsible for transmission of R. felis (Edouard et al. 2014; Jiang et al. 2006; Tay et al. 2014; Tsai et al. 2009; Varagnol et al. 2009; Zhang et al. 2014) and also Rickettsia sp. RF2125 (Tay et al. 2014; Kho et al. 2016). Again, Ct. felis is known to have a worldwide distribution and has been identified throughout Southeast Asia, including China, Hong Kong, Laos and Malaysia (Table 1) (Rust 2017). In addition, the fleas Ct. canis, Xenopsylla cheopsis (Jiang et al. 2006) and Vermipsylla alakurt (mainly distributed in alpine pastoral areas of Northern Asia) have all been demonstrated to be able to harbor rickettsias. Found on sheep, yaks and horses, $V$. alakurt has been demonstrated to be a vector for Candidatus R. barbariae (Zhao et al. 2016).

In Asia, SFGR have recently been detected in other orders although the transmission potential remains unclear. Linognathus setosus, a louse species which can be found on both domesticated and wild dogs, was found to harbor $R$. felis in China (Zhang et al. 2014). Mite species, although not frequently found to be infected, do remain potential biological vectors, such as Leptotrombidium delicenses which was found to harbor organisms related to $R$. australis and R. felis in Taiwan (Tsui et al. 2007) and is distributed throughout Southeast Asia (Lv et al. 2018). Rickettsia akari is known to be transmitted by Liponyssoides sanguineus, the house-mouse mite (Brouqui and Raoult 2006). Melophagus ovinus, the sheep ked, a native to Mongolia and North India, and introduced to Japan, was found to harbor rickettsia highly similar to $R$. raoultii and $R$. slovaca in north-western China (Liu et al. 2016).

Rickettsiae can be both transovarially and trans-staidly transmitted in vectors allowing maintenance of the pathogen within the vector population and vectors acting as reservoirs for the organisms (Parola et al. 2013). For instance with ticks, larvae, nymphs and adults are susceptible to infection and also have the capability to transmit rickettsia (Aung et al. 2014). The number of different SFGR species which a vector may harbor, and the potential for human-vector interactions is intrinsically linked to the geographic distribution of the vector and the local environment, and therefore, the distribution of SFGR is likely to be much wider than anticipated. Rhipicephalus sanguineus has been demonstrated to increase its human affinity with an increase in environmental temperature (Parola et al. 2008), and therefore, its likely significance as a clinically important vector for rickettsiosis may vary across Asia, despite being a globally distributed tick.

\section{Hosts}

Rats and other rodents are common vertebrate hosts of SFGR infections (He et al. 2003; Okabayashi et al. 1996). In Thailand, $62.2 \%$ of rats were found positive for SFGR antibodies (Okabayashi et al. 1996). Bandicota indica rats are the most important hosts of SFGR in this area and are infected mainly by $R$. honei (TT-118) (Okabayashi et al. 1996). A bear and wild pigs were reported to be infected by Rickettsia sp. strain RDla420 and Rickettsia sp. strain RDla440 which are closely related to $R$. bellii and Rickettsia sp. RpA4, respectively (Parola et al. 2003a). Domestic animals such as dogs, cats and sheep can serve as important hosts of SFGR infection to humans due to their close relationship and associated activities with humans (Table 1). SFGR infections in rodents and a few cases in birds are also reported in Taiwan (Kuo et al. 2015, 2017). In addition, monkeys can serve as incidental hosts for Rickettsia sp. RF2125 and its closely related organisms, Candidatus Rickettsia asemboensis and $R$. felis which are detected 
in monkey blood samples (Tay et al. 2015). Rickettsial pathogens do not only infect local people, often travelers have a higher risk of exposure if visiting SFGR endemic areas, and such documented cases include a Taiwanese patient who contracted African tick bite fever after returning from South Africa (Tsai et al. 2009) and a British visitor to Sabah who almost died from SFGR (Lynn et al. 2018).

\section{FACTORS INFLUENCING SFGR EMERGENCE}

\section{Land-Use Change}

Land-use change is a significant driver of emerging infectious diseases. Over the last 300 years, the rapidly growing human population has driven land-use change at unprecedented rates (Ramankutty and Foley 1999). Over $60 \%$ of emerging infectious diseases in the past 6 decades have originated in animals, with nearly half of these linked to changes in land use, agricultural intensification or changes in food production (Burnside et al. 2012; Jones et al. 2008; Keesing et al. 2010; Patz et al. 2004). Zoonotic pathogens, such as Nipah, SARS, bird flu and Ebola, shared between wild or domestic animals account for the majority of emerging infectious diseases (Taylor et al. 2001), while the majority of pathogens (54.3\%) involved in emerging infectious disease events are bacterial or rickettsial (Jones et al. 2008). Increasing contact between people, livestock and wild animals through intensified processes of deforestation, agriculture expansion, land conversion, hunting and urban growth is the driving factor behind this disease emergence (Burnside et al. 2012; Jones et al. 2008; Keesing et al. 2010; Patz et al. 2004).

Asia is the largest continent comprising up to $30 \%$ of the world's land area, and with $60 \%$ of the world's population, it is also the most populated. The estimated population for Asia in 2018 according to UN estimates is 4.5 billion people (Worldometers 2018). Asia has the highest growth rates in the world with its population almost quadrupling during the twentieth century. This rapidly growing population increases pressure for agriculture expansion, land conversion, hunting and urban growth. Currently $48.6 \%$ of Asia's population lives in urban areas, and by 2050 this will have increased to $63 \%$ of the population (Worldometers 2018). As populations continue to grow and the demands for urban living continue to increase, more and more previously pristine environments will be encroached on further driving disease emergence (Foley et al. 2005).

For much of Asia, these pristine environments are forests. Over the past 300 years, global deforestation has resulted in a net loss of between 7 and 11 million $\mathrm{km}^{2}$ of forest - an area the size of the continental USA (Foley et al. 2005; Myers and Patz 2009). According to the 2005 FAO Global Forest Resources Assessment, approximately 13 million hectares of forest are being lost globally to deforestation annually (FAO 2005). While in Asia as a whole, the situation has improved from a net loss in the 1990s to a net gain of forests in 2000-2005, in South and Southeast Asia; however, deforestation continues to increase (FAO 2005). This deforestation caused by agricultural and infrastructure expansion results in the remaining forest patches becoming increasingly fragmented. Currently, approximately $70 \%$ of the world's forests lie within $1 \mathrm{~km}$ of a forest edge (Haddad et al. 2015; Watson et al. 2018). This makes the remaining forest increasingly accessible to human populations and, in turn, makes human and livestock populations increasingly accessible to hosts and vectors for SFGR that live in the forest.

\section{Increased Access to Forest Areas}

As road and other transport networks are improved and expanded, it becomes easier for larger numbers of people to move into or visit previously remote areas, increasing opportunities for contact with vectors and hosts and the potential for SFGR exposure. Pristine and degraded forests are cleared to generate income and to make way for agricultural expansion, extractive industries, expanding transport networks and growing urban areas. As forest fragmentation increases, so does the network of legal and illegal roads around and through them. Initially for access for legal and illegal logging, these roads also provide access to people looking for new areas for agricultural, infrastructure and urban expansion in these previously inaccessible forested regions. As agricultural activities develop in a particular location and governments look to encourage more people to an area, the road networks that serve them begin to improve. As has been seen in Thailand, Cambodia and Sumatra, the growing and improved road network results in increased deforestation, with most logging occurring near roads due to increased accessibility (Clements et al. 2014; Cropper et al. 2001; Miyamoto 2006) further increasing forest fragmentation. A study in Penin- 
sular Malaysia found more than $90 \%$ of snares and poaching camps were located near paved roads (Clements et al. 2014) confirming that as forest fragmentation and road expansion increase, people (including hunters) find it easier to access more forest.

\section{Introduced Vectors}

These new roads in forested areas not only increase human access but also migration (Laurance et al. 2002) bringing more people into areas where they can potentially have contact with the hosts and forest vectors for SFGR. This movement of people can also bring new hosts and vectors such as domestic dogs and their ticks, including the SFGRvector $R$. sanguineus (Scinachi et al. 2017). Recent studies have demonstrated that $R h$. sanguineus exposed to high temperatures feed on humans more rapidly (Parola et al. 2008); therefore, the SFGR risk could increase in rural areas where deforestation results in higher temperatures. The widely distributed $A$. testudinarium is found predominantly in tropical wooded environments (Levin 2018). The increase in forest fragmentation making larger areas of forest accessible, and the corresponding increase in inhabitants farming and living near to the forest edge will increase the potential for contact with such vectors resulting in SFGR spillover.

\section{The Human, Animal, Vector Nexus}

Ticks thrive in the moist and humid environments of the tropics, where they are most commonly found in rural areas; such as forests, grasslands, fields and plantations. Ticks feed on a variety of hosts (Parola et al. 2013) and the tropical areas of South and Southeast Asia, with its high wildlife biodiversity, provide a vast range of hosts for the arthropod species that act as vectors for SFGR. Various studies have demonstrated that people working in rural areas, especially those working in forests, or people involved in deforestation or forest fragmentation and people working in agriculture have a higher risk of being exposed to ticks and potentially SFGR (Quintero et al. 2017; Finch et al. 2014; Tee et al. 1999; Tay et al. 2000).

While the increased funding and the improvement in and adoption of new molecular tools in the last 2 decades have led to an increase in the discovery of novel rickettsia species, and the increase in diagnoses for tick-borne rickettsial diseases, the impact of land-use change across Asia resulting in more people being exposed to SFGR vectors and hosts must also be recognized (Premaratna 2016). These human activities displace wild animals, change vector breeding patterns and force heightened interaction between humans, wildlife and livestock, increasing the chances for the transmission of new diseases, by creating increased opportunities for viruses and bacteria, including SFGR, to jump from wild animal hosts into livestock and domestic animals or directly into people. As SFGR have been demonstrated to be more prevalent in rural areas (Tay et al. 2000, 2003; Tee et al. 1999), rapid economic development and population growth throughout Asia, increasing deforestation and the need for more agricultural land, will bring increasing numbers of people into contact with SFGR vectors and hosts, as human populations move into previously undisturbed areas. While SFGR infections are more common in rural areas (Vallee et al. 2010), people living in urban environment will also be more exposed to SFGR, as rodents and other hosts such as non-human primates adapt to these urban environments (Scientific Committee on Vector-borne Diseases 2013; Tay et al. 2015) and economic development allows more people from urban populations to engage in activities in rural areas such as jungle trekking and other forms of ecotourism, further exposing them to SFGR (Scientific Committee on Vector-borne Diseases 2013; Tay et al. 2003). The potential impact of land-use change on the spread of SFGR greatly increases the urgency for the development of comprehensive detection and response capacities, particularly in "hot spot" areas such as South and Southeast Asia.

Recognizing the link between land-use change and the spread of SFGR also presents an opportunity for low-cost healthcare interventions. Understanding that people working outside in rural areas, especially those working in the forest, involved in deforestation or forest fragmentation and people working in agriculture, are at a higher risk of exposure to vectors and hosts for SFGR allows for more targeted healthcare interventions. Healthcare practitioners working in rural communities need to be reminded to consider suspected rickettsioses including SFGR as one of the potential diagnoses for these high-risk patients presenting with acute febrile illness. There is a need to emphasize the screening of rickettsioses to medical personnel throughout Asia and to encourage the use of appropriate antibiotics as early treatment for nonspecific febrile illnesses in this region (Lynn et al. 2018). Members of these high-risk groups can be taught to recognize their unique risk and to be more vigilant about protecting themselves from ticks and other vectors and seeking med- 
ical treatment when they show symptoms of SFGR or other tick, mite or louse-related illnesses. Similarly, those living in urban areas can be reminded of the habitats that ticks, mites or lice and their hosts prefer and the need to be mindful when in these environments, whether in an urban or rural setting, and to seek medical treatment if experiencing symptoms of SFGR or other tick, mite or louserelated illness after being in these areas. Finally, reducing deforestation, forest fragmentation and land-use change has the potential to reduce disease emergence including SFGR (Quintero et al. 2017). This can be achieved by utilizing science-based, land-use planning tools, for more sustainable land management. Better land-use planning can reduce the scale of land-use change by ensuring that areas selected for land-use change are suitable for and have the highest possible value for its new use.

\section{CONCLUSIONS}

Generally, SFGR infections are significantly neglected and under-recognized in Asia while causing a significant burden of disease. SFGR are not widely studied because of the limitation of diagnostic techniques, but the distribution of this rickettsial group appears to be spreading wider and more cases have been increasingly reported throughout many parts of the world. As the pressure for land-use change continues, the spread and number of SFGR cases are likely to increase due to increased interaction between humans, hosts and vectors. Additionally, SFGR may be one of the main neglected diseases that would place increased financial burden on medical systems, especially in developing countries. Both the development of new strategies, including healthcare interventions targeted at high-risk groups, more informed land-use planning, and the improvement of existing techniques will assist diagnostic capabilities and lead to the appropriate antibiotic treatments for patients which can save and protect people's lives from severe rickettsial infection. Since rickettsial infections have become more globally documented, the growing importance of rickettsia agents and its vector populations have also been increasingly studied and the accumulated information of rickettsial prevalence on human and animal hosts is useful to predict the risk of infection so that we can further identify its pathogenicity on humans. This information allows for control and prevention strategies to be identified, prioritized and implemented.

\section{ACKNOWLEDGEMENTS}

Stuart Blacksell and Matthew Robinson are funded by the Wellcome Trust of the United Kingdom. We wish to thank Paul Bloxham for the maps used in this publication.

\section{OPEn Access}

This article is distributed under the terms of the Creative Commons Attribution 4.0 International License (http://c reativecommons.org/licenses/by/4.0/), which permits unrestricted use, distribution, and reproduction in any medium, provided you give appropriate credit to the original author(s) and the source, provide a link to the Creative Commons license, and indicate if changes were made.

\section{REFERENCES}

Acestor N, Cooksey R, Newton PN, et al. (2012) Mapping the aetiology of non-malarial febrile illness in Southeast Asia through a systematic review-terra incognita impairing treatment policies. PLoS ONE 7(9):e44269. https://doi.org/10.1371/ journal.pone.0044269

Angelakis E, Munasinghe A, Yaddehige I, et al. (2012) Detection of rickettsioses and $\mathrm{Q}$ fever in Sri Lanka. The American Journal of Tropical Medicine and Hygiene 86(4):711-712. https://doi.org/ 10.4269/ajtmh.2012.11-0424

Aung AK, Spelman DW, Murray RJ, Graves S (2014) Rickettsial infections in Southeast Asia: implications for local populace and febrile returned travelers. The American Journal of Tropical Medicine and Hygiene 91(3):451-460. https://doi.org/10.4269/ ajtmh.14-0191

Barbara KA, Farzeli A, Ibrahim IN, et al. (2010) Rickettsial infections of fleas collected from small mammals on four islands in Indonesia. Journal of Medical Entomology 47(6):1173-1178

Bhengsri S, Baggett HC, Edouard S, et al. (2016) Sennetsu neorickettsiosis, spotted fever group, and typhus group rickettsioses in three provinces in Thailand. The American Journal of Tropical Medicine and Hygiene 95(1):43-49. https://doi.org/ 10.4269/ajtmh.15-0752

Brouqui P, Raoult D (2006) Arthropod-borne diseases in homeless. Annals of the New York Academy of Sciences 1078:223-235. https://doi.org/10.1196/annals.1374.041

Burnside WR, Brown JH, Burger O, Hamilton MJ, Moses M, Bettencourt LM (2012) Human macroecology: linking pattern and process in big-picture human ecology. Biological reviews of the Cambridge Philosophical Society 87(1):194-208. https:// doi.org/10.1111/j.1469-185X.2011.00192.x

Camer GA, Alejandria M, Amor M, et al. (2003) Detection of antibodies against spotted fever group Rickettsia (SFGR), typhus group Rickettsia (TGR), and Coxiella burnetii in human febrile patients in the Philippines. Japanese Journal of Infectious Diseases 56(1):26-28 
Cane R (2010) Haemaphysalis longicornis Neumann, 1901 In: Profile New Zealand Biosecure Entomology Laboratory. https:// www.smsl.co.nz/site/southernmonitoring/files/NZB/Ha\%20lon gicornis\%20Profile.pdf. Accessed 4 December 2018

Chikeka I, Dumler JS (2015) Neglected bacterial zoonoses. Clinical Microbiology and Infection 21(5):404-415. https://doi.org/ 10.1016/j.cmi.2015.04.022

Choi YJ, Jang WJ, Ryu JS, et al. (2005) Spotted fever group and typhus group rickettsioses in humans, South Korea. Emerging Infectious Diseases 11(2):237-244. https://doi.org/10.3201/ eid1102.040603

Clements GR, Lynam AJ, Gaveau D, et al. (2014) Where and how are roads endangering mammals in Southeast Asia's forests? PLoS ONE 9(12):e115376. https://doi.org/10.1371/journal.pone. 0115376

Colonne PM, Eremeeva ME, Sahni SK (2011) Beta interferonmediated activation of signal transducer and activator of transcription protein 1 interferes with Rickettsia conorii replication in human endothelial cells. Infection and Immunity 79(9):37333743. https://doi.org/10.1128/IAI.05008-11

Cropper M, Puri J, Griffiths C (2001) Predicting the location of deforestation: The role of roads and protected areas in North Thailand. Land Economics 77:172-186

Dittrich S, Phommasone K, Anantatat T, et al. (2014) Rickettsia felis infections and comorbid conditions, Laos, 2003-2011. Emerging Infectious Diseases 20(8):1402-1404. https://doi.org/ 10.3201/eid2008.131308

Edouard S, Bhengsri S, Dowell SF, Watt G, Parola P, Raoult D (2014) Two human cases of Rickettsia felis infection, Thailand. Emerging Infectious Diseases 20(10):1780-1781. https://doi.org/ 10.3201/eid2010.140905

FAO (2005) Global Forest Resources Assessment 2005 FAO Forestry Paper 147

Faruque LI, Zaman RU, Gurley ES, et al. (2017) Prevalence and clinical presentation of Rickettsia, Coxiella, Leptospira, Bartonella and chikungunya virus infections among hospital-based febrile patients from December 2008 to November 2009 in Bangladesh. BMC Infectious Diseases 17(1):141. https://doi.org/ 10.1186/s12879-017-2239-6

Finch C, Al-Damluji MS, Krause PJ, Niccolai L, Steeves T, O’Keefe CF, Diuk-Wasser MA (2014) Integrated assessment of behavioral and environmental risk factors for Lyme disease infection on Block Island, Rhode Island. PLoS ONE 9:e84758

Foley JA, Defries R, Asner GP, et al. (2005) Global consequences of land use. Science 309(5734):570-574. https://doi.org/10.1126/ science. 1111772

Fournier PE, Fujita H, Takada N, Raoult D (2002) Genetic identification of rickettsiae isolated from ticks in Japan. Journal of Clinical Microbiology 40(6):2176-2181

Fournier PE, Raoult D (2009) Current knowledge on phylogeny and taxonomy of Rickettsia spp. Annals of the New York Academy of Sciences 1166:1-11. https://doi.org/10.1111/j.17496632.2009.04528.x

Gillespie JJ, Williams K, Shukla M, et al. (2008) Rickettsia phylogenomics: unwinding the intricacies of obligate intracellular life. PLoS ONE 3(4):e2018. https://doi.org/10.1371/journal.pone. 0002018

Graves S, Stenos J (2009) Rickettsioses in Australia. Annals of the New York Academy of Sciences 1166:151-155. https://doi.org/ 10.1111/j.1749-6632.2009.04530.x

Gray J, Dantas-Torres F, Estrada-Pena A, Levin M (2013) Systematics and ecology of the brown dog tick, Rhipicephalus sanguineus. Ticks and Tick-borne Diseases 4(3):171-180. https:// doi.org/10.1016/j.ttbdis.2012.12.003

Guo LP, Jiang SH, Liu D, Wang SW, Chen CF, Wang YZ (2016) Emerging spotted fever group rickettsiae in ticks, northwestern China. Ticks and Tick-borne Diseases 7(6):1146-1150. https:// doi.org/10.1016/j.ttbdis.2016.08.006

Haddad NM, Brudvig LA, Clobert J, et al. (2015) Habitat fragmentation and its lasting impact on Earth's ecosystems. Science Advances 1(2):e1500052. https://doi.org/10.1126/sciadv.1500052

Han R, Yang J, Niu Q, et al. (2018) Molecular prevalence of spotted fever group rickettsiae in ticks from Qinghai Province, northwestern China. Infection, Genetics and Evolution 57:1-7. https://doi.org/10.1016/j.meegid.2017.10.025

He JF, Zheng K, Li W, et al. (2003) Study on spotted fever group Rickettsiae in Guangdong province. Zhonghua Liu Xing Bing Xue Za Zhi 24(8):700-703

Hechemy KE, Raoult D, Fox J, Han Y, Elliott LB, Rawlings J (1989) Cross-reaction of immune sera from patients with rickettsial diseases. Journal of Medical Microbiology 29(3):199_ 202. https://doi.org/10.1099/00222615-29-3-199

Imaoka K, Kaneko S, Tabara K, Kusatake K, Morita E (2011) The First Human Case of Rickettsia tamurae Infection in Japan. Case Reports in Dermatology 3(1):68-73. https://doi.org/10.1159/ 000326941

Inpankaew T, Hii SF, Chimnoi W, Traub RJ (2016) Canine vector-borne pathogens in semi-domesticated dogs residing in northern Cambodia. Parasites and Vectors 9(1):253. https:// doi.org/10.1186/s13071-016-1552-Z

Ishiguro F, Takada N, Fujita H, Noji Y, Yano Y, Iwasaki H (2008) Survey of the vectorial competence of ticks in an endemic area of spotted fever group rickettsioses in Fukui Prefecture, Japan. Microbiology and Immunology 52(6):305-309. https://doi.org/ 10.1111/j.1348-0421.2008.00042.x

Izzard L, Fuller A, Blacksell SD, et al. (2010) Isolation of a novel Orientia species (O. chuto sp. nov.) from a patient infected in Dubai. Journal of Clinical Microbiology 48(12):4404-4409. https://doi.org/10.1128/jcm.01526-10

Jang WJ, Choi YJ, Kim JH, et al. (2005) Seroepidemiology of spotted fever group and typhus group rickettsioses in humans, South Korea. Microbiology and Immunology 49(1):17-24

Jiang J, Sangkasuwan V, Lerdthusnee K, et al. (2005) Human Infection with Rickettsia honei, Thailand. Emerging Infectious Diseases 11(9):1473-1475. https://doi.org/10.3201/ eid1109.050111

Jiang J, Soeatmadji DW, Henry KM, Ratiwayanto S, Bangs MJ, Richards AL (2006) Rickettsia felis in Xenopsylla cheopis, Java, Indonesia. Emerging Infectious Diseases 12(8):1281-1283. https://doi.org/10.3201/eid1208.060327

Jones KE, Patel NG, Levy MA, et al. (2008) Global trends in emerging infectious diseases. Nature 451(7181):990-993. https://doi.org/10.1038/nature06536

Kalal BS, Puranik P, Nagaraj S, Rego S, Shet A (2016) Scrub typhus and spotted fever among hospitalised children in South India: Clinical profile and serological epidemiology. Indian Journal of Medical Microbiology 34(3):293-298. https://doi.org/ 10.4103/0255-0857.188315

Kato CY, Chung IH, Robinson LK, Austin AL, Dasch GA, Massung RF (2013) Assessment of real-time PCR assay for detection of Rickettsia spp. and Rickettsia rickettsii in banked clinical samples. Journal of Clinical Microbiology 51(1):314-317. https:// doi.org/10.1128/jcm.01723-12 
Keesing F, Belden LK, Daszak P, et al. (2010) Impacts of biodiversity on the emergence and transmission of infectious diseases. Nature 468(7324):647-652. https://doi.org/10.1038/ nature09575

Khan SA, Bora T, Chattopadhyay S, Jiang J, Richards AL, Dutta P (2016) Seroepidemiology of rickettsial infections in Northeast India. Transactions of The Royal Society of Tropical Medicine and Hygiene 110(8):487-494. https://doi.org/10.1093/trstmh/trw052

Kho KL, Koh FX, Hasan LI, et al. (2017) Rickettsial seropositivity in the indigenous community and animal farm workers, and vector surveillance in Peninsular Malaysia. Emerging Microbes \& Infections 6(4):e18. https://doi.org/10.1038/emi.2017.4

Kho KL, Koh FX, Singh HKL, Zan HAM, Ponnampalavanar S, Kukreja A, Tay ST (2016) Spotted fever group rickettsioses and murine typhus in a Malaysian teaching hospital. The American Journal of Tropical Medicine and Hygiene 95:765-768. https:// doi.org/10.4269/ajtmh.16-0199

Kollars TM Jr, Tippayachai B, Bodhidatta D (2001) Short report: Thai tick typhus, Rickettsia honei, and a unique rickettsia detected in Ixodes granulatus (Ixodidae: Acari) from Thailand. The American Journal of Tropical Medicine and Hygiene 65(5):535537

Kularatne SA, Edirisingha JS, Gawarammana IB, Urakami H, Chenchittikul M, Kaiho I (2003) Emerging rickettsial infections in Sri Lanka: the pattern in the hilly Central Province. Tropical Medicine and International Health 8(9):803-811

Kularatne SA, Rajapakse RP, Wickramasinghe WM, et al. (2013) Rickettsioses in the central hills of Sri Lanka: serological evidence of increasing burden of spotted fever group. International Journal of Infectious Diseases 17(11):e988-e992. https://doi.org/ 10.1016/j.ijid.2013.05.014

Kuo CC, Huang JL, Lin TE, Wang HC (2012) Detection of Rickettsia spp. and host and habitat associations of fleas (Siphonaptera) in eastern Taiwan. Med Vet Entomol 26(3):341350. https://doi.org/10.1111/j.1365-2915.2012.01009.x

Kuo CC, Lin YF, Yao CT, et al. (2017) Tick-borne pathogens in ticks collected from birds in Taiwan. Parasites and Vectors 10(1):587. https://doi.org/10.1186/s13071-017-2535-4

Kuo CC, Shu PY, Mu JJ, Wang HC (2015) High prevalence of Rickettsia spp. infections in small mammals in Taiwan. VectorBorne and Zoonotic Diseases 15(1):13-20. https://doi.org/ 10.1089/vbz.2014.1584

La Scola B, Raoult D (1997) Laboratory diagnosis of rickettsioses: current approaches to diagnosis of old and new rickettsial diseases. Journal of Clinical Microbiology 35(11):2715-2727

Lai CH, Chang LL, Lin JN, et al. (2014) Human spotted fever group rickettsioses are underappreciated in southern Taiwan, particularly for the species closely-related to Rickettsia felis. PLoS ONE 9(4):e95810. https://doi.org/10.1371/journal.pone.0095810

Laurance WF, Albernaz AKM, Schroth G, et al. (2002) Predictors of deforestation in the Brazilian Amazon. Journal of Biogeography 29:737-748

Lee JH, Park HS, Jung KD, et al. (2003) Identification of the spotted fever group rickettsiae detected from Haemaphysalis longicornis in Korea. Microbiology and Immunology 47(4):301304

Levin ML (2018) Ambylomma spp. In: MSD Manual: Veterinary Manual. https://www.msdvetmanual.com/integumentary-syste m/ticks/amblyomma-spp. Accessed 10 December 2018

Li H, Cui XM, Cui N, et al. (2016) Human infection with novel spotted fever group Rickettsia genotype, China, 2015. Emerging
Infectious Diseases 22(12):2153-2156. https://doi.org/10.3201/ eid2212.160962

Li H, Zhang PH, Huang Y, et al. (2018) Isolation and identification of Rickettsia raoultii in human cases: a surveillance study in 3 medical centers in China. Clinical Infectious Diseases 66(7):1109-1115. https://doi.org/10.1093/cid/cix917

Liu D, Wang YZ, Zhang H, et al. (2016) First report of Rickettsia raoultii and $R$. slovaca in Melophagus ovinus, the sheep ked. Parasites and Vectors 9(1):600. https://doi.org/10.1186/s13071016-1885-7

Luce-Fedrow A, Mullins K, Kostik AP, St John HK, Jiang J, Richards AL (2015) Strategies for detecting rickettsiae and diagnosing rickettsial diseases. Future Microbiology 10(4):537-564. https://doi.org/10.2217/fmb.14.141

Lv Y, Guo XG, Jin DC (2018) Research progress on Leptotrombidium deliense. The Korean Journal of Parasitology 56(4):313324. https://doi.org/10.3347/kjp.2018.56.4.313

Lynn MS, William T, Tanganuchitcharnchai A, et al. (2018) Spotted fever rickettsiosis in a wildlife researcher in Sabah, Malaysia: a case study. Tropical Medicine and Infectious Disease $3(1): 1$

Ma SK, Wong WC, Leung CW, et al. (2011) Review of vector-borne diseases in Hong Kong. Travel Medicine and Infectious Disease 9(3):95-105. https://doi.org/10.1016/j.tmaid.2010.01.004

Mahara F (1997) Japanese spotted fever: report of 31 cases and review of the literature. Emerging Infectious Diseases 3(2):105111. https://doi.org/10.3201/eid0302.970203

Merhej V, Angelakis E, Socolovschi C, Raoult D (2014) Genotyping, evolution and epidemiological findings of Rickettsia species. Infection, Genetics and Evolution 25:122-137. https:// doi.org/10.1016/j.meegid.2014.03.014

Miyamoto M (2006) Forest conversion to rubber around Sumatran villages in Indonesia: comparing the impacts of road construction, transmigration projects and population. Forest Policy and Economics 9:1-12

Myers SS, Patz JA (2009) Emerging threats to human health from global environmental change. Annual Review of Environment and Resources 34(1):223-252

Nagalingam K, Rolain JM, Thevanesam V, Lakkumar F, Gunawardana G, Raoult D (2009) Spotted fever rickettsioses in children in Sri Lanka. Clinical Microbiology and Infection 15(Suppl 2):330-331. https://doi.org/10.1111/j.14690691.2008.02262.x

Nanayakkara DM, Rajapakse RP, Wickramasinghe S, Kularatne SA (2013) Serological evidence for exposure of dogs to Rickettsia conorii, Rickettsia typhi, and Orientia tsutsugamushi in Sri Lanka. Vector-Borne and Zoonotic Diseases 13(8):545-549. https:// doi.org/10.1089/vbz.2012.1049

Niang M, Parola P, Tissot-Dupont H, Baidi L, Brouqui P, Raoult D (1998) Prevalence of antibodies to Rickettsia conorii, Ricketsia africae, Rickettsia typhi and Coxiella burnetii in Mauritania. Eur J Epidemiol 14(8):817-818

Noh Y, Lee YS, Kim HC, et al. (2017) Molecular detection of Rickettsia species in ticks collected from the southwestern provinces of the Republic of Korea. Parasites and Vectors 10(1):20. https://doi.org/10.1186/s13071-016-1955-X

Okabayashi T, Tsutiya K, Muramatsu Y, Ueno H, Morita C (1996) Serological survey of spotted fever group rickettsia in wild rats in Thailand in the 1970s. Microbiology and Immunology 40(12):895-898

Parola P (2004) Tick-borne rickettsial diseases: emerging risks in Europe. Comparative Immunology, Microbiology and Infectious 
Diseases 27(5):297-304. https://doi.org/10.1016/j.cimid.2004.03.006

Parola P, Cornet JP, Sanogo YO, et al. (2003) Detection of Ehrlichia spp., Anaplasma spp., Rickettsia spp., and other eubacteria in ticks from the Thai-Myanmar border and Vietnam. Journal of Clinical Microbiology 41(4):1600-1608

Parola P, Fenollar F, Badiaga S, Brouqui P, Raoult D (2001) First documentation of Rickettsia conorii infection (strain Indian tick typhus) in a Traveler. Emerging Infectious Diseases 7(5):909-910. https://doi.org/10.3201/eid0705.017527

Parola P, Miller RS, McDaniel P, et al. (2003) Emerging rickettsioses of the Thai-Myanmar border. Emerging Infectious Diseases 9(5):592-595

Parola P, Paddock CD, Socolovschi C, et al. (2013) Update on tick-borne rickettsioses around the world: a geographic approach. Clinical Microbiology Reviews 26(4):657-702. https:// doi.org/10.1128/CMR.00032-13

Parola P, Socolovschi C, Jeanjean L, et al. (2008) Warmer weather linked to tick attack and emergence of severe rickettsioses. PLoS Neglected Tropical Diseases 2(11):e338. https://doi.org/10.1371/ journal.pntd.0000338

Patz JA, Daszak P, Tabor GM, et al. (2004) Unhealthy landscapes: policy recommendations on land use change and infectious disease emergence. Environmental Health Perspectives 112(10):1092-1098

Perez-Osorio CE, Zavala-Velazquez JE, Arias Leon JJ, ZavalaCastro JE (2008) Rickettsia felis as emergent global threat for humans. Emerging Infectious Diseases 14(7):1019-1023. https:// doi.org/10.3201/eid1407.071656

Phongmany S, Rolain JM, Phetsouvanh R, et al. (2006) Rickettsial infections and fever, Vientiane, Laos. Emerging Infectious Diseases 12(2):256-262. https://doi.org/10.3201/eid1202.050900

PicKard AL, McDaniel P, Miller RS, et al. (2004) A study of febrile illnesses on the Thai-Myanmar border: predictive factors of rickettsioses. The Southeast Asian Journal of Tropical Medicine and Public Health 35(3):657-663

Premaratna R (2016) Epidemiology and ecology of rickettsial Infections. International Journal of Infectious Diseases 45S:1-477

Premaratna R, Ariyaratna N, Attanayake C, Bandara W, Chandrasena N, de Silva HJ (2014) Rickettsial infection among military personnel deployed in Northern Sri Lanka. BMC Infectious Diseases 14:3864. https://doi.org/10.1186/s12879-0140688-8

Premaratna R, Loftis AD, Chandrasena TG, Dasch GA, de Silva HJ (2008) Rickettsial infections and their clinical presentations in the Western Province of Sri Lanka: a hospital-based study. International Journal of Infectious Diseases 12(2):198-202. https:// doi.org/10.1016/j.ijid.2007.06.009

Quintero VJ, Paternina TL, Uribe YA, et al. (2017) Eco-epidemiological analysis of rickettsial seropositivity in rural areas of Colombia: a multilevel approach. PLoS Neglected Tropical Diseases 11(9):e0005892. https://doi.org/10.1371/journal.pntd.0005892

Ramankutty N, Foley J (1999) Estimating historical changes in global land cover: croplands from 1700 to 1992. Global Biogeochemical Cycles 13(4):997-1027

Rathi NB, Rathi AN, Goodman MH, Aghai ZH (2011) Rickettsial diseases in central India: proposed clinical scoring system for early detection of spotted fever. Indian Pediatrics 48(11):867872

Richards AL, Ratiwayanto S, Rahardjo E, et al. (2003) Serologic evidence of infection with ehrlichiae and spotted fever group rickettsiae among residents of Gag Island, Indonesia. The American Journal of Tropical Medicine and Hygiene 68(4):480484

Robertson RG, Wisseman CL Jr (1973) Tick-borne rickettsiae of the spotted fever group in West Pakistan. II. Serological classification of isolates from West Pakistan and Thailand: evidence for two new species. American Journal of Epidemiology 97(1):5564

Rodkvamtook W, Gaywee J, Kanjanavanit S, et al. (2013) Scrub typhus outbreak, northern Thailand, 2006-2007. Emerging Infectious Diseases 19(5):774-777. https://doi.org/10.3201/ eid1905.121445

Rust MK (2017) The biology and ecology of cat fleas and advancements in their pest management: a review. Insects 8(4):118. https://doi.org/10.3390/insects 8040118

Rydkina E, Turpin LC, Sahni SK (2010) Rickettsia rickettsii infection of human macrovascular and microvascular endothelial cells reveals activation of both common and cell type-specific host response mechanisms. Infection and Immunity 78(6):2599-2606. https://doi.org/10.1128/IAI.01335-09

Satoh H, Tsuneki A, Inokuma H, Kumazawa N, Jahana Y, Kiyuuna T, Okabayashi T, Muramatsu Y, Ueno H, Morita C (2001) Seroprevalence of antibodies against spotted fever group rickettsia among dogs and humans in Okinawa, Japan. Microbiology and Immunology 45:85-87

Scientific Committee on Vector-borne Diseases (2013) Epidemiology, Prevention and Control of Spotted Fever in Hong Kong

Scinachi CA, Takeda G, Mucci LF, Pinter A (2017) Association of the occurrence of Brazilian spotted fever and Atlantic rain forest fragmentation in the Sao Paulo metropolitan region, Brazil. Acta Tropica 166:225-233. https://doi.org/10.1016/j.actatropica.2016.11.025

Sentausa E, El Karkouri K, Robert C, Raoult D, Fournier PE (2012) Genome sequence of Rickettsia conorii subsp. indica, the agent of Indian tick typhus. Journal of Bacteriology 194(12):3288-3289

Slapeta J, Lawrence A, Reichel MP (2018) Cat fleas (Ctenocephalides felis) carrying Rickettsia felis and Bartonella species in Hong Kong. Parasitology international 67(2):209-212. https:// doi.org/10.1016/j.parint.2017.12.001

Stenos J, Roux V, Walker D, Raoult D (1998) Rickettsia honei sp. nov., the aetiological agent of Flinders Island spotted fever in Australia. International Journal of Systematic and Evolutionary Microbiology 4:1399-1404. https://doi.org/10.1099/0020771348-4-1399

Sun J, Lin J, Gong Z, et al. (2015) Detection of spotted fever group Rickettsiae in ticks from Zhejiang Province, China. Experimental and Applied Acarology 65(3):403-411. https://doi.org/10.1007/ s10493-015-9880-9

Tay ST, Ho TM, Rohani MY, Devi S (2000) Antibodies to Orientia tsutsugamushi, Rickettsia typhi and spotted fever group rickettsiae among febrile patients in rural areas of Malaysia. Transactions of the Royal Society of Tropical Medicine and $\mathrm{Hy}$ giene 94(3):280-284

Tay ST, Kamalanathan M, Rohani MY (2003) Antibody prevalence of Orientia tsutsugamushi, Rickettsia typhi and TT118 spotted fever group rickettsiae among Malaysian blood donors and febrile patients in the urban areas. The Southeast Asian Journal of Tropical Medicine and Public Health 34(1):165-170

Tay ST, Koh FX, Kho KL, Sitam FT (2015) Rickettsial infections in monkeys, Malaysia. Emerging Infectious Diseases 21(3):545-547. https://doi.org/10.3201/eid2103.141457 
Tay ST, Mokhtar AS, Low KC, et al. (2014) Identification of rickettsiae from wild rats and cat fleas in Malaysia. Medical and Veterinary Entomology 28(Suppl 1):104-108. https://doi.org/ $10.1111 /$ mve. 12075

Tay ST, Rohani MY (2002) The use of the indirect immunoperoxidase test for the serodiagnosis of rickettsial diseases in Malaysia. The Southeast Asian Journal of Tropical Medicine and Public Health 33(2):314-320

Taylor AJ, Vongphayloth K, Vongsouvath M, et al. (2016) Largescale survey for tickborne bacteria, Khammouan Province, Laos. Emerging Infectious Diseases 22(9):1635-1639. https://doi.org/ 10.3201/eid2209.151969

Taylor LH, Latham SM, Woolhouse ME (2001) Risk factors for human disease emergence. Philosophical Transactions of The Royal Society B Biology Science 356(1411):983-989. https:// doi.org/10.1098/rstb.2001.0888

Tee TS, Kamalanathan M, Suan KA, et al. (1999) Seroepidemiologic survey of Orientia tsutsugamushi, Rickettsia typhi, and TT118 spotted fever group rickettsiae in rubber estate workers in Malaysia. The American Journal of Tropical Medicine and Hygiene 61(1):73-77

Trung NV, Hoi LT, Thuong NTH, et al. (2017) Seroprevalence of scrub typhus, typhus, and spotted fever among rural and urban populations of northern Vietnam. The American Journal of Tropical Medicine and Hygiene 96(5):1084-1087. https://doi.org/ 10.4269/ajtmh.16-0399

Tsai KH, Lu HY, Huang JH, et al. (2009) African tick bite Fever in a Taiwanese traveler returning from South Africa: molecular and serologic studies. The American Journal of Tropical Medicine and Hygiene 81(5):735-739. https://doi.org/10.4269/ ajtmh.2009.09-0101

Tsai KH, Lu HY, Tsai JJ, Yu SK, Huang JH, Shu PY (2008) Human case of Rickettsia felis infection, Taiwan. Emerging Infectious Diseases 14(12):1970-1972. https://doi.org/10.3201/eid1412.08 0515

Tsui PY, Tsai KH, Weng MH, et al. (2007) Molecular detection and characterization of spotted fever group rickettsiae in Taiwan. The American Journal of Tropical Medicine and Hygiene 77(5):883-890
Vallee J, Thaojaikong T, Moore CE, et al. (2010) Contrasting spatial distribution and risk factors for past infection with scrub typhus and murine typhus in Vientiane City, Lao PDR. PLoS Neglected Tropical Diseases 4(12):e909. https://doi.org/10.1371/ journal.pntd.0000909

Varagnol M, Parola P, Jouan R, Beaucournu JC, Rolain JM, Raoult D (2009) First detection of Rickettsia felis and Bartonella clarridgeiae in fleas from Laos. Clinical Microbiology and Infection 15(Suppl 2):334-335. https://doi.org/10.1111/j.14690691.2008.02272.x

Vitorino L, Chelo IM, Bacellar F, Ze-Ze L (2007) Rickettsiae phylogeny: a multigenic approach. Microbiology 153(Pt 1):160 168. https://doi.org/10.1099/mic.0.2006/001149-0

Watson JEM, Evans T, Venter O, et al. (2018) The exceptional value of intact forest ecosystems. Nature Ecology and Evolution 2(4):599-610. https://doi.org/10.1038/s41559-018-0490-x

Wei QQ, Guo LP, Wang AD, et al. (2015) The first detection of Rickettsia aeschlimannii and Rickettsia massiliae in Rhipicephalus turanicus ticks, in northwest China. Parasites and Vectors 8:631. https://doi.org/10.1186/s13071-015-1242-2

Worldometers (2018) Asia Population. In. http://www.worldome ters.info/world-population/asia-population. Accessed 30 May 2018

Yang J, Tian Z, Liu Z, et al. (2016) Novel spotted fever group rickettsiae in Haemaphysalis qinghaiensis ticks from Gansu, Northwest China. Parasites and Vectors 9:146. https://doi.org/ 10.1186/s13071-016-1423-7

Zhang J, Lu G, Kelly P, et al. (2014) First report of Rickettsia felis in China. BMC Infectious Diseases 14:682. https://doi.org/ 10.1186/s12879-014-0682-1

Zhang JZ, Fan MY, Wu YM, Fournier PE, Roux V, Raoult D (2000) Genetic classification of "Rickettsia heilongjiangii" and "Rickettsia hulinii," two Chinese spotted fever group rickettsiae. Journal of Clinical Microbiology 38(9):3498-3501

Zhao SS, Li HY, Yin XP, Liu ZQ, Chen CF, Wang YZ (2016) First detection of Candidatus Rickettsia barbariae in the flea Vermipsylla alakurt from north-western China. Parasites and Vectors 9(1):325. https://doi.org/10.1186/s13071-016-1614-2 